\title{
Prefrontal Cortical Thickness Deficit in Detoxified Alcohol-dependent Patients
}

\author{
Sujin Bae ${ }^{1 \dagger}$, Ilhyang Kang ${ }^{2,3 \dagger}$, Boung Chul Lee ${ }^{4}$, Yujin Jeon ${ }^{2}$, Han Byul Cho ${ }^{5}$, \\ Sujung Yoon ${ }^{2,3}$, Soo Mee Lim ${ }^{6}$, Jungyoon $\mathrm{Kim}^{2}$, In Kyoon Lyoo ${ }^{2,3,7}$, \\ Jieun E Kim ${ }^{2,3 *}$ and Ihn-Geun Choi ${ }^{8 *}$ \\ ${ }^{1}$ Industry Academic Cooperation Foundation, Chung-Ang University, Seoul 06974, \\ ${ }^{2}$ Ewha Brain Institute, Ewha Womans University, Seoul 03760, \\ ${ }^{3}$ Department of Brain and Cognitive Sciences, Ewha Womans University, Seoul 03760, \\ ${ }^{4}$ Department of Neuropsychiatry, Hallym University Hangang Sacred Heart Hospital, Seoul 07247, Korea \\ ${ }^{5}$ The Brain Institute, University of Utah, Salt Lake City, UT 84108, USA \\ ${ }^{6}$ Department of Radiology, Ewha Womans University College of Medicine, Seoul 03760, \\ ${ }^{7}$ College of Pharmacy, Graduate School of Pharmaceutical Sciences, Ewha Womans University, Seoul 03760, \\ ${ }^{8}$ Department of Psychiatry, Hallym University Kangnam Sacred Heart Hospital, Seoul 07441, Korea
}

\begin{abstract}
Alcohol dependence is a serious disorder that can be related with a number of potential health-related and social consequences. Cortical thickness measurements would provide important information on the cortical structural alterations in patients with alcohol dependence. Twenty-one patients with alcohol dependence and 22 healthy comparison subjects have been recruited and underwent high-resolution brain magnetic resonance (MR) imaging and clinical assessments. T1-weighted MR images were analyzed using the cortical thickness analysis program. Significantly thinner cortical thickness in patients with alcohol dependence than healthy comparison subjects was noted in the left superior frontal cortical region, correcting for multiple comparisons and adjusting with age and hemispheric average cortical thickness. There was a significant association between thickness in the cluster of the left superior frontal cortex and the duration of alcohol use. The prefrontal cortical region may particularly be vulnerable to chronic alcohol exposure. It is also possible that the pre-existing deficit in this region may have rendered individuals more susceptible to alcohol dependence.
\end{abstract}

Key words: Alcoholism, Cerebral Cortex, Frontal Lobe, Magnetic Resonance Imaging

Received August 21,2016, Revised December 14,2016,

Accepted December 23, 2016

* To whom correspondence should be addressed.

Jieun E Kim, TEL: 82-2-3277-6932, FAX: 82-2-3277-6562

e-mail:kjieun@ewha.ac.kr

Ihn-Geun Choi, TEL: 82-2-829-5187, FAX: 82-2-849-4469

e-mail: ihngeun@hallym.or.kr

These authors contributed equally to this work.

\section{INTRODUCTION}

Alcohol dependence is the most prevalent substance use disorder [1] that can lead individuals with the disorder to serious healthrelated $[2,3]$ and social problems $[4,5]$. According to a report by Nutt and colleagues (2007), the level of potential harm and risk of alcohol use and misuse was among the top five with heroin and cocaine [6]. The 12-month prevalence of alcohol dependence is 
reported to be approximately $2 \%$ to $6 \%$ in the general populations [7-9].

In part reflecting the high potential harm and high prevalence of alcohol dependence, there have been a number of studies on how chronic alcohol use or alcohol dependence interacts with the structure of the brain of animals [10-13] and humans [14-21]. Overall brain atrophy, including the lesser volumes of gray matter and white matter with increased cerebrospinal fluid, in patients with alcohol use disorders, has consistently been reported [22$24]$. Deficits in the prefrontal cortex [16, 25], temporal cortex [14, 20,26], cerebellum [14], striatum, hippocampus and amygdala [14, 27-29] have also been reported in patients with alcohol dependence. Neuropathological studies have shown that the alcohol-related neuronal and glial loss would preferentially involve the prefrontal cortex $[30,31]$ among cortical regions. Functional neuroimaging studies demonstrated altered metabolism or activation of the frontal cortex in association with the deteriorated neuropsychological functioning [32-34].

Cortical thickness analysis, a reliable and valid method [35, 36], can capture important information on cortical structures [37]. However, relatively few studies have investigated cortical thickness in alcohol-dependent adults [38-40]. Durazzo and colleagues exhibited that alcohol-dependent adults had thinner cortical regions in the left anterior cingulate cortex, bilateral frontal cortex, and bilateral insula than healthy controls [38]. Other researchers found that alcohol-dependent adults had reduced cortical thickness in the widespread brain regions of the superior frontal, precentral, postcentral, middle frontal, middle and superior temporal, middle temporal, and the lateral occipital cortex than healthy comparison participants [39]. In the report by Momenan and colleagues, participants with alcohol dependence exhibited thinner cortical regions that encompass the medial superior frontal cortex, insula, precentral and the precuneus of the right hemisphere as well as the superior frontal gyrus of the left hemisphere, in comparison with the healthy controls [40].

Previous studies have reported widespread cortical deficits without covarying out the effects associated with the global atrophy of the brain [38-40]. Among these widespread regions that show alcohol-related atrophy, we wanted to localize the cortical regions that may be particularly vulnerable to alcohol consumption. We therefore undertook the cortical thickness analysis adjusting for the hemispheric average cortical thickness, in 21 detoxified alcohol-dependent patients and matched 22 healthy comparison subjects. The objective of this study was to identify brain regions with cortical thickness alterations that exceed the level of global alterations in alcohol dependence. We used the whole brain-wise cortical thickness analysis, which is validated histologically [36] and with manual outlining method [35]. We also investigated whether the magnitude of deficits are correlated with the alcohol use-related variable.

Given the studies that suggest the preferential involvement of prefrontal cortex among brain structural and functional alterations in alcohol dependence [16, 25, 31-33, 41, 42], we hypothesized that patients with alcohol dependence would have thinner prefrontal cortex in comparison with healthy comparison subjects, after correcting for the global cortical thinning associated with alcohol dependence.

\section{MATERIALS AND METHODS}

\section{Subjects}

Patients with alcohol dependence were enrolled from the Inpatient Unit of the Department of Neuropsychiatry in a university-affiliated hospital, Seoul, South Korea. Age-matched healthy comparison subjects were recruited from the community via the local advertisement during the same study period. Age was matched at the group-level. This study was performed from January 2007 to January 2009.

Inclusion criteria for alcohol dependence group were (1) age between 20 and 70, and (2) diagnosis of alcohol dependence according to the Diagnostic and Statistical Manual of Mental Disorders-IV by 2 board-certified psychiatrists.

Exclusion criteria for both alcohol dependence and control groups were (1) any symptoms or signs of confusion, major medical disorders including kidney disease and chronic liver disease, and/or malnutrition, (2) presence or history of neurological disorders, (3) presence or history of any mental disorders other than alcohol dependence or comorbid depressive disorders, including alcohol-induced persistent dementia, alcoholinduced amnestic disorder, or alcohol withdrawal delirium (3) history of head injury, and (4) any contraindications to magnetic resonance imaging (MRI) such as pace makers, claustrophobia, or metal implants.

Additional exclusion criteria for control group were (1) presence or history of mental disorders including alcohol abuse and (2) current alcohol consumption greater than 14 equivalent standard drinks for men, 7 for women, per time [43].

After being detoxified for 2 weeks, all patients underwent physical examination by a physician and the routine laboratory tests to screen out any major medical disorders. Clinical evaluation was performed by a board-certified psychiatrist. MRI evaluations were performed under the supervision of the key investigators. The study was approved by the University Institutional Review Board. All subjects provided written informed consent before 
study participation.

\section{Brain magnetic resonance (MR) image acquisition and cortical thickness analysis}

T1 and T2 weighted MR images were obtained using 1.5 Tesla Siemens whole body scanner. T1 weighted images of 43 subjects were obtained with following image acquisition protocol. Repetition time $[\mathrm{TR}]=2,050 \mathrm{~ms}$, echo time $[\mathrm{TE}]=4.39 \mathrm{~ms}$, inversion time $[\mathrm{TI}]=1,100 \mathrm{~ms}$, number of excitation $[\mathrm{NEX}]=2$, flip angle $[\mathrm{FA}]=15^{\circ}$, slice thickness $=1.3 \mathrm{~mm}$, field of view $[\mathrm{FOV}]=180 \times 180 \mathrm{~mm}$, acquisition matrix $=256 \times 180$. T1 weighted images of 7 subjects were obtained with slightly different image acquisition protocol $(\mathrm{TR}=1,960 \mathrm{~ms}, \mathrm{TE}=4.38 \mathrm{~ms}, \mathrm{TI}=1,100 \mathrm{~ms}$, $\mathrm{NEX}=2$, flip angle $[\mathrm{FA}]=15^{\circ}$, slice thickness $=1.5 \mathrm{~mm}, \mathrm{FOV}=250$ $X 250$, acquisition matrix $=256$ X 180). T2 weighted images were acquired in order to screen for gross brain abnormality $(\mathrm{TR}=9,710$ $\mathrm{ms}, \mathrm{TE}=120 \mathrm{~ms}, \mathrm{NEX}=2$, flip angle $[\mathrm{FA}]=170^{\circ}$, slice thickness $=3$ $\mathrm{mm})$.

Measurements of cortical thickness were conducted by using the cortical surface-based analysis $[44,45]$. Detailed procedures of the cortical thickness analysis are described elsewhere [46]. Smoothing processes were conducted using an iterative nearestneighbor averaging procedure with the full-width half maximum (FWHM) 15 mm 2-D Gaussian kernel [45].

\section{Statistical analysis}

For calculating statistical difference maps of cortical thickness between alcohol dependence and healthy comparison groups, general linear model (GLM) with cortical thickness at each vertex as the dependent variable has been used. Non-cortical areas of medial wall and corpus callosum were excluded from the model building $[47,48]$. Hemispheric average cortical thickness was included in the model as a covariate since there was a significant difference in hemispheric average cortical thickness between groups and our aim was to identify the particularly vulnerable cortical regions beyond the global brain atrophy associated with alcohol dependence. Age was also included as a covariate. To correct for multiple comparisons, 5,000 permutation simulations have been performed with random group-label shuffling, with a threshold for a significant vertex of $\mathrm{p}<0.05[49,50]$. Clusters with the size that would pass the family-wise error rate correction were considered significant [50].

Thickness values of the surface point with highest $\mathrm{z}$ values (local maxima) within the cluster, where significant group differences of cortical thickness were found, were extracted for post hoc analyses. Pair-wise correlations were used to test whether there were associations between the magnitude of cortical thickness deficits in patients with alcohol dependence and the duration of alcohol use [21].

Considering the relatively modest sample size, sensitivity analyses to rule out the possibility that the current results may be modulated by other confounding factors such as comorbid depression, anxiety symptoms and scan parameter difference were performed $[51,52]$. Local maxima thickness values within the cluster extracted as described above were subjected to linear regression models that included the scan parameter difference, the presence of comorbid depression as defined by 19 or more scores on the 17-item Hamilton Depression Rating Scale (HDRS) [53], or the presence of anxiety as defined by 40 or more scores on the State-Trait Anxiety Inventory (STAI-T) $[54,55]$ as additional covariates.

Data are presented as means \pm standard deviations. Computations were performed using STATA version 11 (Stata corp., College Station, TX, USA). Two-tailed $\mathrm{p}<0.05$ was considered significant.

\section{RESULTS}

There were no significant differences in age and sex between diagnostic groups (Table 1). Patients with alcohol dependence drank alcohol more frequently and more heavily than healthy comparison subjects (Table 1).

Patients with alcohol dependence had general cortical thinning (left hemispheric average cortical thickness (mm): $2.44 \pm 0.07$ [healthy comparison subjects] vs $2.24 \pm 0.27$ [patients with alcohol dependence], $t=3.35, \mathrm{p}=0.002$ ) (right hemispheric average cortical thickness (mm): $2.45 \pm 0.07$ [healthy comparison subjects] vs $2.25 \pm 0.23$ [patients with alcohol dependence], $t=3.77, \mathrm{p}<0.001$ ). In order to identify regionally specific cortical deficits in patients with alcohol dependence compared to healthy comparison subjects, hemispheric average cortical thickness was added as a covariate in the whole brain vertex-wise analysis. In the GLM model that includes age and average cortical thickness as covariates, significant cortical thickness deficits in patients with alcohol dependence, compared to healthy comparison subjects, were noted in the left superior frontal cortex, after correcting for multiple comparisons with the permutation method (Fig. 1) (cluster size $=1489.5 \mathrm{~mm}^{2}$; number of vertices in the cluster $=2,035$; Talairach coordinates $=\mathrm{x}$ $[-15.3], y[61.8], z$ [5.0]; cluster $\mathrm{p}$ value $=0.024)$.

Given that different scanning parameter may influence on the cortical thickness variations [51], analysis was re-run with scan parameter as a covariate. Trend level significance was noted $(\mathrm{p}=0.091)$. When analysis was repeated covarying for comorbid depression that may be associated with thinner prefrontotemporal cortex $[31,52,56]$, the diagnostic group effect remained 
Table 1. Characteristics of participants

\begin{tabular}{|c|c|c|c|c|c|}
\hline \multirow{2}{*}{ Demographic variables } & \multirow{2}{*}{$\begin{array}{c}\text { Patients } \\
\text { with alcohol } \\
\text { dependence }(\mathrm{N}=21)\end{array}$} & \multirow{2}{*}{$\begin{array}{c}\text { Healthy } \\
\text { comparison } \\
\text { subjects }(\mathrm{N}=22)\end{array}$} & \multicolumn{3}{|c|}{ Statistical values } \\
\hline & & & & & \\
\hline Age, years & $50.6(8.2)$ & $50.2(8.1)$ & $t=0.17$ & $d f=41$ & $\mathrm{p}=0.861$ \\
\hline Sex, male/female & $18 / 3$ & $19 / 3$ & & & $\mathrm{p}=0.645^{\mathrm{a}}$ \\
\hline \multicolumn{6}{|l|}{ Alcohol use variables } \\
\hline Duration of alcohol use, years & $32.1(11.5)$ & $30.0(8.7)$ & $t=0.65$ & $d f=37$ & $\mathrm{p}=0.523$ \\
\hline Frequency of alcohol use, times per month & $19.4(8.0)$ & $2.0(2.2)$ & $t=9.71$ & $d f=37$ & $\mathrm{p}<0.001$ \\
\hline Average alcohol dose, standard drinks ${ }^{\mathrm{b}}$ per time & $6.9(3.6)$ & $2.0(1.8)$ & $t=5.53$ & $d f=37$ & $\mathrm{p}<0.001$ \\
\hline Alcohol Use Disorders Identification Test (AUDIT) scores & $22.1(7.4)$ & $3.8(3.7)$ & $t=10.06$ & $d f=37$ & $\mathrm{p}<0.001$ \\
\hline Clinical Institute Withdrawal Assessment for Alcohol (CIWA) scores & $6.8(8.8)$ & $1.0(1.1)$ & $t=3.10$ & $d f=37$ & $\mathrm{p}=0.004$ \\
\hline \multicolumn{6}{|l|}{ Other clinical variables } \\
\hline Comorbid depression $^{c}$ & $4(24)$ & $0(0)$ & & & $\mathrm{p}=0.029^{\mathrm{a}}$ \\
\hline Comorbid anxiety $^{\mathrm{d}}$ & $11(65)$ & $3(14)$ & & & $\mathrm{p}=0.002^{\mathrm{a}}$ \\
\hline
\end{tabular}

Data are expressed as mean (standard deviations) or numbers (\%).

${ }^{a}$ Fisher's exact test.

${ }^{\mathrm{b}}$ One standard drink contains 14 gram of alcohol.

'Presence of depression was defined as $\geq 19$ on the 17 -item Hamilton Rating Scale for Depression.

${ }^{\mathrm{d}}$ Presence of anxiety was defined as $\geq 40$ on the State-Trait Anxiety Inventory.

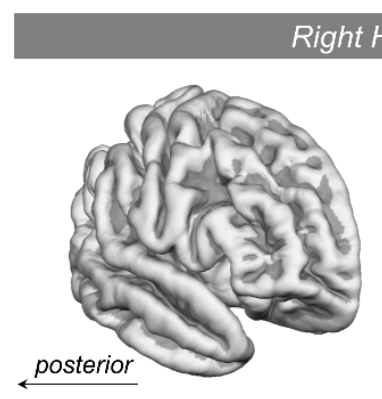

\section{Right Hemisphere}

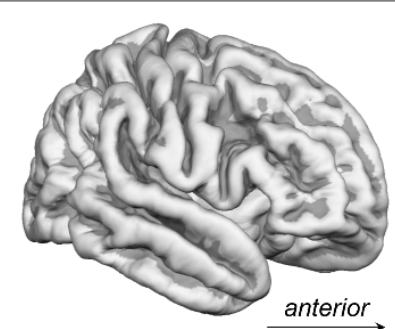

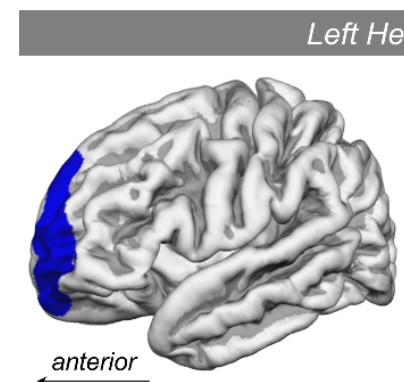

anterior
Left Hemisphere

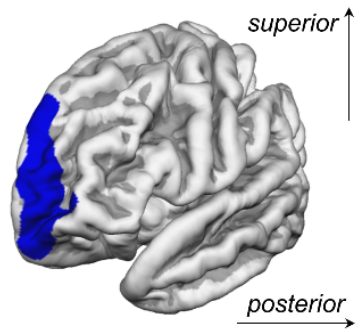

Significant cortical thickness differences between alcohol dependence and healthy comparison groups (Alcohol $<$ Control, multiple comparison corrected $P<0.05$ )

Fig. 1. The cortical region with significant cortical thickness differences between alcohol dependence $(\mathrm{N}=21)$ and healthy comparison groups $(\mathrm{N}=22)$. Multiple comparisons were corrected using the permutation tests of 5,000 iterations of random shuffling the group labeling. Clusters that pass the threshold for multiple comparison correction with family-wise error correction cluster size inferences are shown here. Covariates were age and hemispheric average cortical thickness.

significant $(\mathrm{p}=0.001)$. When analysis was repeated covarying for comorbid anxiety that may also be associated with thinner prefronto-temporal cortex $[57,58]$, the diagnostic group effect remained significant in the left superior frontal cluster $(\mathrm{p}=0.017)$.

Post hoc correlation analysis between cortical thicknesses in the left superior frontal cluster of significant group difference and duration of alcohol use in alcohol dependence group demonstrated the significant association ( $r=-0.55 ; \mathrm{p}=0.02)$ (Fig. 2 ). Cortical thicknesses in the left superior frontal cluster was also correlated with the Clinical Institute Withdrawal Assessment for Alcohol scores $(r=-0.548, \mathrm{p}=0.028)$. Otherwise we found no significant results between cortical thicknesses in the left superior frontal cluster and AUDIT scores ( $r=0.048, \mathrm{p}=0.859)$; and calculated alcohol use (alcohol dose x frequency x duration) ( $r=-0.193$, $\mathrm{p}=0.509$ ).

\section{DISCUSSION}

In the current study, we have identified the brain region with altered cortical thickness in patients with alcohol dependence. The region of cortical thickness deficits in patients with alcohol dependence encompassed primarily the superior frontal cortex, after adjusting for the effects on the global cortical atrophy induced by alcohol dependence (Fig. 1). 


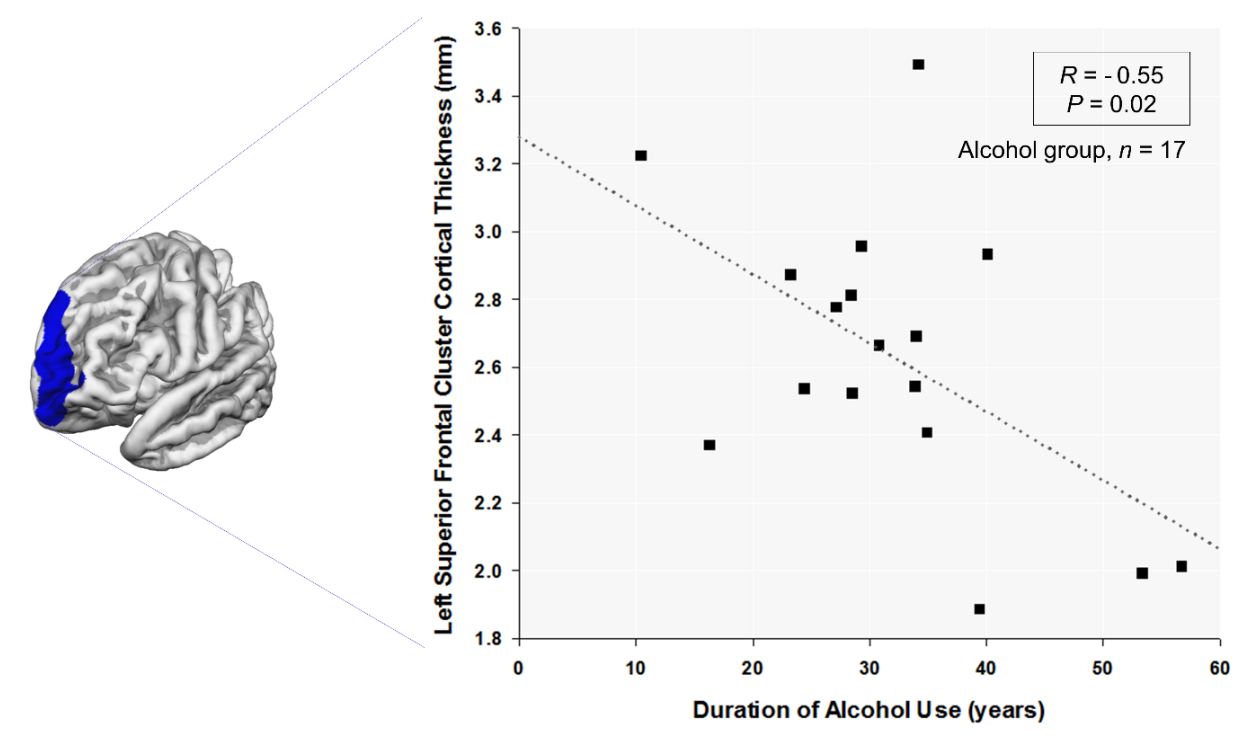

Fig. 2. Correlation between mean cortical thickness of the left superior frontal cortical cluster ${ }^{\mathrm{a}}$ and duration of

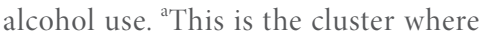
the significant diagnostic group effect was noted after correcting for multiple comparisons using the permutation methods.
This is consistent with prior reports indicating that chronic alcohol use may have the most detrimental effects on prefrontal cortical regions $[26,59,60]$. The level of $\mathrm{N}$-acetyl aspartate, the viability marker of neurons, was decreased in prefrontal brain regions in chronic alcohol abusers [61]. Neuronal and glial loss has consistently been noted in the prefrontal cortical regions, particularly in the superior frontal cortex [30, 62-64]. Alcohol use has been associated with the decreased performances in executive and attention tasks that are important function of the prefrontal cortex [49].

The superior frontal cortex has a key role in the reward circuitry [65]. Pre-existing vulnerability in these regions may predispose individuals to alcohol dependence [65], since the function of these regions are to executively control over drug craving and seeking. These regions may be associated with the compulsive substancerelated behaviors [66], which is also in line with our finding that shows the association between duration of alcohol use with the magnitude of the cortical deficits in this region.

The current findings do not provide information regarding whether the pre-existing prefrontal cortical deficits have rendered individuals vulnerable to alcohol dependence [18], whether neurotoxicity of chronic alcohol use, including the oxidative stress [67], have damaged the cortex, or whether both processes have contributed to the observed findings. Supporting evidence for the neurotoxicity as the cause of prefrontal deficits may come from the reports that show patients with longer abstinence have lesser deficits [68]. It has also been suggested that subjects with alcohol dependence may have prefrontal cortex that are less recuperative from toxic effects and may undergo vicious cycle after initial exposure to substances $[65,69]$. Considering that alcohol dependence can be divided into two subtypes, type 1 more environmentally influenced, and type 2 more genetically induced [70,71], a comparison between type 1 and type 2 alcohol dependent patients in a study with larger sample with balanced composition of type 1 and type 2 alcohol dependence may provide an opportunity to approach this question. Longitudinal brain imaging study that follows up patients with alcohol dependence would also provide important insights.

This study alone does not provide direct information as to cellular level mechanisms that may underlie the observed deficits of the cortical thickness. However, there is a vast literature describing the impact of chronic alcohol on the brain [12, 21, 26, 31, 72]. Miguel-Hidalgo and colleagues (2002) reported, in their study with the postmortem brain of alcohol-dependent patients without Wernicke or Korsakoff syndromes, that the glial pathology of reduced size and density was the most characteristic finding. Kril and colleagues (1997) have shown selective loss of nonGABAergic pyramidal neurons. Selective dendritic retraction, rather than cellular death, has been suggested as main pathology related to the volume loss of the gray matter [73].

There is a study that examined the cortical thickness differences in subjects with fetal alcohol syndrome or prenatal alcohol exposure, compared to control subjects [74], which demonstrated deficits in prefronto-temporo-parietal regions. However, few studies have examined cortical thickness in alcohol-dependent adults [38-40]. The cortical thickness analysis has been reported to provide information on an important aspect of the gray matter structure, complementary to the conventional volumetry or the VBM $[37,44,75]$. For example, highly folded regions could have high gray matter density in VBM analysis since there would be 
more voxels of gray matter within a fixed radius, but thinner cortical thickness [37]. This is the first study that used cortical thickness analysis in patients with alcohol dependence excluding comorbid substance use, which showed regionally specific cortical thickness deficits in alcohol dependence.

There are limitations of the current study. Relatively modest sample size may limit the generalizability of the findings. Large age range, though covaried in the statistical model, can be another weakness of the study. With the current study of a cross-sectional design, information on whether the observed cortical deficits would be progressive and could be recovered with abstinence cannot be provided. Nicotine dependence, which is highly comorbid with alcohol dependence, has also been reported to be associated with cortical atrophy, particularly that in frontal cortex [76]. Now that we neither were able to exclude participants with co-morbid nicotine dependence nor delineate the effects of alcohol dependence from those of nicotine dependence, the current results may have been confounded by the effects of chronic nicotine use. Intellectual ability has also been reported to be associated with the prefrontal cortical development [77]. The fact that the intelligence quotient was not included in the statistical model for comparisons of cortical thickness measures, is also an important limitation of the current study. Future studies in larger samples with narrow age range and with neuropsychological assessments for the frontal lobe function, would provide valuable information. Although there could be challenges in following up patients with alcohol dependence, long-term prospective longitudinal study is also warranted.

\section{ACKNOWLEDGEMENTS}

This study was supported by the Korea Research Foundation Grant funded by the Korean Government (MOEHRD)(KRF2006-E00351, Dr. Choi), the Fire Fighting Safety \& 119 Rescue Technology Research and Development Program funded by the Ministry of Public Safety and Security (MPSS-Fire Fighting Safety-2016-86, Dr. Kim), and the Brain Research Program of the National Research Foundation of Korea funded by the Ministry of Science, ICT \& Future Planning (2015M3C7A1028376, Dr. Kim). The sponsors had no role in study design; in the collection, analysis, and interpretation of the data; in the preparation of the manuscript; and in the decision to submit the article for publication. We thank Dr. Chansoo Jun, Dr. Hyeonseok S Jeong, and Ms. Jihye Choi for technical assistance.

\section{REFERENCES}

1. Murray CJ, Lopez AD (1996) Evidence-based health policy-lessons from the global burden of disease study. Science 274:740-743.

2. Grant BF, Stinson FS, Dawson DA, Chou SP, Dufour MC, Compton W, Pickering RP, Kaplan K (2004) Prevalence and co-occurrence of substance use disorders and independent mood and anxiety disorders: results from the national epidemiologic survey on alcohol and related conditions. Arch Gen Psychiatry 61:807-816.

3. Moss HB, Chen CM, Yi HY (2010) Prospective follow-up of empirically derived alcohol dependence subtypes in wave 2 of the national epidemiologic survey on alcohol and related conditions (NESARC): recovery status, alcohol use disorders and diagnostic criteria, alcohol consumption behavior, health status, and treatment seeking. Alcohol Clin Exp Res 34:10731083.

4. Caetano R, Schafer J, Cunradi CB (2001) Alcohol-related intimate partner violence among white, black, and Hispanic couples in the United States. Alcohol Res Health 25:58-65.

5. Chou SP, Dawson DA, Stinson FS, Huang B, Pickering RP, Zhou Y, Grant BF (2006) The prevalence of drinking and driving in the United States, 2001-2002: results from the national epidemiological survey on alcohol and related conditions. Drug Alcohol Depend 83:137-146.

6. Nutt D, King LA, Saulsbury W, Blakemore C (2007) Development of a rational scale to assess the harm of drugs of potential misuse. Lancet 369:1047-1053.

7. Hasin DS, Stinson FS, Ogburn E, Grant BF (2007) Prevalence, correlates, disability, and comorbidity of DSM-IV alcohol abuse and dependence in the United States: results from the national epidemiologic survey on alcohol and related conditions. Arch Gen Psychiatry 64:830-842.

8. Xiang YT, Ma X, Lu JY, Cai ZJ, Li SR, Xiang YQ, Guo HL, Hou YZ, Li ZB, Li ZJ, Tao YF, Dang WM, Wu XM, Deng J, Lai KY, Ungvari GS (2009) Alcohol-related disorders in Beijing, China: prevalence, socio-demographic correlates, and unmet need for treatment. Alcohol Clin Exp Res 33:1111-1118.

9. Cho MJ, Kim JK, Jeon HJ, Suh T, Chung IW, Hong JP, Bae JN, Lee DW, Park JI, Cho SJ, Lee CK, Hahm BJ (2007) Lifetime and 12-month prevalence of DSM-IV psychiatric disorders among Korean adults. J Nerv Ment Dis 195:203-210.

10. Dlugos CA, Pentney RJ (2000) Effects of chronic ethanol consumption on SER of Purkinje neurons in old F344 rats. Alcohol 20:125-132.

11. Green JT, Tran T, Steinmetz JE, Goodlett CR (2002) Neonatal 
ethanol produces cerebellar deep nuclear cell loss and correlated disruption of eyeblink conditioning in adult rats. Brain Res 956:302-311.

12. Mooney SM, Napper RM (2005) Early postnatal exposure to alcohol reduces the number of neurons in the occipital but not the parietal cortex of the rat. Alcohol Clin Exp Res 29:683-691.

13. Nixon K, Crews FT (2002) Binge ethanol exposure decreases neurogenesis in adult rat hippocampus. J Neurochem 83:1087-1093.

14. Chanraud S, Martelli C, Delain F, Kostogianni N, Douaud G, Aubin HJ, Reynaud M, Martinot JL (2007) Brain morphometry and cognitive performance in detoxified alcohol-dependents with preserved psychosocial functioning. Neuropsychopharmacology 32:429-438.

15. Chanraud S, Leroy C, Martelli C, Kostogianni N, Delain F, Aubin HJ, Reynaud M, Martinot JL (2009) Episodic memory in detoxified alcoholics: contribution of grey matter microstructure alteration. PLoS One 4:e6786.

16. Fein G, Di Sclafani V, Cardenas VA, Goldmann H, TolouShams M, Meyerhoff DJ (2002) Cortical gray matter loss in treatment-naïve alcohol dependent individuals. Alcohol Clin Exp Res 26:558-564.

17. Fortier CB, Leritz EC, Salat DH, Lindemer E, Maksimovskiy AL, Shepel J, Williams V, Venne JR, Milberg WP, McGlinchey RE (2014) Widespread effects of alcohol on white matter microstructure. Alcohol Clin Exp Res 38:2925-2933.

18. Hill SY, Wang S, Kostelnik B, Carter H, Holmes B, McDermott M, Zezza N, Stiffler S, Keshavan MS (2009) Disruption of orbitofrontal cortex laterality in offspring from multiplex alcohol dependence families. Biol Psychiatry 65:129-136.

19. Makris N, Oscar-Berman M, Jaffin SK, Hodge SM, Kennedy DN, Caviness VS, Marinkovic K, Breiter HC, Gasic GP, Harris GJ (2008) Decreased volume of the brain reward system in alcoholism. Biol Psychiatry 64:192-202.

20. Mechtcheriakov S, Brenneis C, Egger K, Koppelstaetter F, Schocke M, Marksteiner J (2007) A widespread distinct pattern of cerebral atrophy in patients with alcohol addiction revealed by voxel-based morphometry. J Neurol Neurosurg Psychiatry 78:610-614.

21. Miguel-Hidalgo JJ, Overholser JC, Meltzer HY, Stockmeier CA, Rajkowska G (2006) Reduced glial and neuronal packing density in the orbitofrontal cortex in alcohol dependence and its relationship with suicide and duration of alcohol dependence. Alcohol Clin Exp Res 30:1845-1855.

22. Agartz I, Momenan R, Rawlings RR, Kerich MJ, Hommer DW (1999) Hippocampal volume in patients with alcohol dependence. Arch Gen Psychiatry 56:356-363.

23. Agartz I, Shoaf S, Rawlings RR, Momenan R, Hommer DW (2003) CSF monoamine metabolites and MRI brain volumes in alcohol dependence. Psychiatry Res 122:21-35.

24. Pfefferbaum A, Rosenbloom M, Deshmukh A, Sullivan E (2001) Sex differences in the effects of alcohol on brain structure. Am J Psychiatry 158:188-197.

25. Lim KO, Choi SJ, Pomara N, Wolkin A, Rotrosen JP (2002) Reduced frontal white matter integrity in cocaine dependence: a controlled diffusion tensor imaging study. Biol Psychiatry 51:890-895.

26. Kril JJ, Halliday GM, Svoboda MD, Cartwright H (1997) The cerebral cortex is damaged in chronic alcoholics. Neuroscience 79:983-998.

27. De Bellis MD, Clark DB, Beers SR, Soloff PH, Boring AM, Hall J, Kersh A, Keshavan MS (2000) Hippocampal volume in adolescent-onset alcohol use disorders. Am J Psychiatry 157:737-744.

28. Ozsoy S, Durak AC, Esel E (2013) Hippocampal volumes and cognitive functions in adult alcoholic patients with adolescent-onset. Alcohol 47:9-14.

29. Wrase J, Makris N, Braus DF, Mann K, Smolka MN, Kennedy DN, Caviness VS, Hodge SM, Tang L, Albaugh M, Ziegler DA, Davis OC, Kissling C, Schumann G, Breiter HC, Heinz A (2008) Amygdala volume associated with alcohol abuse relapse and craving. Am J Psychiatry 165:1179-1184.

30. Harper C, Kril J, Daly J (1987) Are we drinking our neurones away? Br Med J (Clin Res Ed) 294:534-536.

31. Miguel-Hidalgo JJ, Wei J, Andrew M, Overholser JC, Jurjus G, Stockmeier CA, Rajkowska G (2002) Glia pathology in the prefrontal cortex in alcohol dependence with and without depressive symptoms. Biol Psychiatry 52:1121-1133.

32. Adams KM, Gilman S, Koeppe RA, Kluin KJ, Brunberg JA, Dede D, Berent S, Kroll PD (1993) Neuropsychological deficits are correlated with frontal hypometabolism in positron emission tomography studies of older alcoholic patients. Alcohol Clin Exp Res 17:205-210.

33. Adams KM, Gilman S, Koeppe R, Kluin K, Junck L, Lohman M, Johnson-Greene D, Berent S, Dede D, Kroll P (1995) Correlation of neuropsychological function with cerebral metabolic rate in subdivisions of frontal lobes of older alcoholic patients measured with $[-1-8 \mathrm{~F}]$ fluorodeoxyglucose and positron emission tomography. Neuropsychology 9:275-280.

34. Trick L, Kempton MJ, Williams SC, Duka T (2014) Impaired fear recognition and attentional set-shifting is associated with brain structural changes in alcoholic patients. Addict Biol 
19:1041-1054.

35. Kuperberg GR, Broome MR, McGuire PK, David AS, Eddy M, Ozawa F, Goff D, West WC, Williams SC, van der Kouwe AJ, Salat DH, Dale AM, Fischl B (2003) Regionally localized thinning of the cerebral cortex in schizophrenia. Arch Gen Psychiatry 60:878-888.

36. Rosas HD, Liu AK, Hersch S, Glessner M, Ferrante RJ, Salat DH, van der Kouwe A, Jenkins BG, Dale AM, Fischl B (2002) Regional and progressive thinning of the cortical ribbon in Huntington's disease. Neurology 58:695-701.

37. Panizzon MS, Fennema-Notestine C, Eyler LT, Jernigan TL, Prom-Wormley E, Neale M, Jacobson K, Lyons MJ, Grant MD, Franz CE, Xian H, Tsuang M, Fischl B, Seidman L, Dale A, Kremen WS (2009) Distinct genetic influences on cortical surface area and cortical thickness. Cereb Cortex 19:27282735.

38. Durazzo TC, Tosun D, Buckley S, Gazdzinski S, Mon A, Fryer SL, Meyerhoff DJ (2011) Cortical thickness, surface area, and volume of the brain reward system in alcohol dependence: relationships to relapse and extended abstinence. Alcohol Clin Exp Res 35:1187-1200.

39. Fortier CB, Leritz EC, Salat DH, Venne JR, Maksimovskiy AL, Williams V, Milberg WP, McGlinchey RE (2011) Reduced cortical thickness in abstinent alcoholics and association with alcoholic behavior. Alcohol Clin Exp Res 35:2193-2201.

40. Momenan R, Steckler LE, Saad ZS, van Rafelghem S, Kerich MJ, Hommer DW (2012) Effects of alcohol dependence on cortical thickness as determined by magnetic resonance imaging. Psychiatry Res 204:101-111.

41. De Bellis MD, Narasimhan A, Thatcher DL, Keshavan MS, Soloff P, Clark DB (2005) Prefrontal cortex, thalamus, and cerebellar volumes in adolescents and young adults with adolescent-onset alcohol use disorders and comorbid mental disorders. Alcohol Clin Exp Res 29:1590-1600.

42. Harper C (1998) The neuropathology of alcohol-specific brain damage, or does alcohol damage the brain? J Neuropathol Exp Neurol 57:101-110.

43. Dawson DA, Grant BF, Li TK (2005) Quantifying the risks associated with exceeding recommended drinking limits. Alcohol Clin Exp Res 29:902-908.

44. Dale AM, Fischl B, Sereno MI (1999) Cortical surfacebased analysis. I. Segmentation and surface reconstruction. Neuroimage 9:179-194.

45. Fischl B, Dale AM (2000) Measuring the thickness of the human cerebral cortex from magnetic resonance images. Proc Natl Acad Sci U S A 97:11050-11055.

46. Lyoo IK, Sung YH, Dager SR, Friedman SD, Lee JY, Kim SI,
Kim N, Dunner DL, Renshaw PF (2006) Regional cerebral cortical thinning in bipolar disorder. Bipolar Disord 8:65-74.

47. Fjell AM, Westlye LT, Greve DN, Fischl B, Benner T, van der Kouwe AJ, Salat D, Bjørnerud A, Due-Tønnessen P, Walhovd KB (2008) The relationship between diffusion tensor imaging and volumetry as measures of white matter properties. Neuroimage 42:1654-1668.

48. Janssen J, Reig S, Alemán Y, Schnack H, Udias JM, Parellada M, Graell M, Moreno D, Zabala A, Balaban E, Desco M, Arango C (2009) Gyral and sulcal cortical thinning in adolescents with first episode early-onset psychosis. Biol Psychiatry 66:1047-1054.

49. Bullmore ET, Suckling J, Overmeyer S, Rabe-Hesketh S, Taylor E, Brammer MJ (1999) Global, voxel, and cluster tests, by theory and permutation, for a difference between two groups of structural MR images of the brain. IEEE Trans Med Imaging 18:32-42.

50. Hayasaka S, Nichols TE (2003) Validating cluster size inference: random field and permutation methods. Neuroimage 20:2343-2356.

51. Han X, Jovicich J, Salat D, van der Kouwe A, Quinn B, Czanner S, Busa E, Pacheco J, Albert M, Killiany R, Maguire P, Rosas D, Makris N, Dale A, Dickerson B, Fischl B (2006) Reliability of MRI-derived measurements of human cerebral cortical thickness: the effects of field strength, scanner upgrade and manufacturer. Neuroimage 32:180-194.

52. Peterson BS, Warner V, Bansal R, Zhu H, Hao X, Liu J, Durkin K, Adams PB, Wickramaratne P, Weissman MM (2009) Cortical thinning in persons at increased familial risk for major depression. Proc Natl Acad Sci U S A 106:6273-6278.

53. Hamilton M (1960) A rating scale for depression. J Neurol Neurosurg Psychiatry 23:56-62.

54. Knight RG, Waal-Manning HJ, Spears GF (1983) Some norms and reliability data for the state-trait anxiety inventory and the Zung self-rating depression scale. Br J Clin Psychol 22:245-249.

55. Spielberger CD, Gorsuch RL, Lushene RE, Vagg PR, Jacobs GA (1983) Manual for the state-trait anxiety inventory. Consulting Psychologists Press, Palo Alto, CA.

56. Kremen WS, O'Brien RC, Panizzon MS, Prom-Wormley E, Eaves LJ, Eisen SA, Eyler LT, Hauger RL, Fennema-Notestine C, Fischl B, Grant MD, Hellhammer DH, Jak AJ, Jacobson KC, Jernigan TL, Lupien SJ, Lyons MJ, Mendoza SP, Neale MC, Seidman LJ, Thermenos HW, Tsuang MT, Dale AM, Franz CE (2010) Salivary cortisol and prefrontal cortical thickness in middle-aged men: a twin study. Neuroimage 53:1093-1102.

57. Sobanski T, Wagner G, Peikert G, Gruhn U, Schluttig K, 
Sauer H, Schlösser R (2010) Temporal and right frontal lobe alterations in panic disorder: a quantitative volumetric and voxel-based morphometric MRI study. Psychol Med 40:18791886.

58. Spampinato MV, Wood JN, De Simone V, Grafman J (2009) Neural correlates of anxiety in healthy volunteers: a voxelbased morphometry study. J Neuropsychiatry Clin Neurosci 21:199-205.

59. Abernathy K, Chandler LJ, Woodward JJ (2010) Alcohol and the prefrontal cortex. Int Rev Neurobiol 91:289-320.

60. Medina KL, McQueeny T, Nagel BJ, Hanson KL, Schweinsburg AD, Tapert SF (2008) Prefrontal cortex volumes in adolescents with alcohol use disorders: unique gender effects. Alcohol Clin Exp Res 32:386-394.

61. Schweinsburg BC, Taylor MJ, Alhassoon OM, Videen JS, Brown GG, Patterson TL, Berger F, Grant I (2001) Chemical pathology in brain white matter of recently detoxified alcoholics: a $1 \mathrm{H}$ magnetic resonance spectroscopy investigation of alcohol-associated frontal lobe injury. Alcohol Clin Exp Res 25:924-934.

62. Harper C, Corbett D (1990) Changes in the basal dendrites of cortical pyramidal cells from alcoholic patients--a quantitative Golgi study. J Neurol Neurosurg Psychiatry 53:856-861.

63. Harper C, Kril J (1989) Patterns of neuronal loss in the cerebral cortex in chronic alcoholic patients. J Neurol Sci 92:81-89.

64. Kril JJ, Harper CG (1989) Neuronal counts from four cortical regions of alcoholic brains. Acta Neuropathol 79:200-204.

65. Kalivas PW, Volkow ND (2005) The neural basis of addiction: a pathology of motivation and choice. Am J Psychiatry 162:1403-1413.

66. Volkow ND, Li TK (2004) Drug addiction: the neurobiology of behaviour gone awry. Nat Rev Neurosci 5:963-970.

67. Flatscher-Bader T, Wilce PA (2008) Impact of alcohol abuse on protein expression of midkine and excitatory amino acid transporter 1 in the human prefrontal cortex. Alcohol Clin Exp Res 32:1849-1858.

68. Kim SJ, Lyoo IK, Hwang J, Chung A, Hoon Sung Y, Kim J,
Kwon DH, Chang KH, Renshaw PF (2006) Prefrontal greymatter changes in short-term and long-term abstinent methamphetamine abusers. Int J Neuropsychopharmacol 9:221-228.

69. Wobrock T, Falkai P, Schneider-Axmann T, Frommann N, Wölwer W, Gaebel W (2009) Effects of abstinence on brain morphology in alcoholism: a MRI study. Eur Arch Psychiatry Clin Neurosci 259:143-150.

70. Choi IG, Kee BS, Son HG, Ham BJ, Yang BH, Kim SH, Lee JS, Son BK, Lee BY, Lee SY, Chai YG, Shin HD (2006) Genetic polymorphisms of alcohol and aldehyde dehydrogenase, dopamine and serotonin transporters in familial and nonfamilial alcoholism. Eur Neuropsychopharmacol 16:123-128.

71. Cloninger CR (1987) Neurogenetic adaptive mechanisms in alcoholism. Science 236:410-416.

72. Kril JJ (1995) The contribution of alcohol, thiamine deficiency and cirrhosis of the liver to cerebral cortical damage in alcoholics. Metab Brain Dis 10:9-16.

73. Jensen GB, Pakkenberg B (1993) Do alcoholics drink their neurons away? Lancet 342:1201-1204.

74. Sowell ER, Mattson SN, Kan E, Thompson PM, Riley EP, Toga AW (2008) Abnormal cortical thickness and brain-behavior correlation patterns in individuals with heavy prenatal alcohol exposure. Cereb Cortex 18:136-144.

75. Thompson PM, Hayashi KM, Sowell ER, Gogtay N, Giedd JN, Rapoport JL, de Zubicaray GI, Janke AL, Rose SE, Semple J, Doddrell DM, Wang Y, van Erp TG, Cannon TD, Toga AW (2004) Mapping cortical change in Alzheimer's disease, brain development, and schizophrenia. Neuroimage 23 Suppl 1:S2S18.

76. Li Y, Yuan K, Cai C, Feng D, Yin J, Bi Y, Shi S, Yu D, Jin C, von Deneen KM, Qin W, Tian J (2015) Reduced frontal cortical thickness and increased caudate volume within fronto-striatal circuits in young adult smokers. Drug Alcohol Depend 151:211-219.

77. Shaw P, Greenstein D, Lerch J, Clasen L, Lenroot R, Gogtay N, Evans A, Rapoport J, Giedd J (2006) Intellectual ability and cortical development in children and adolescents. Nature 440:676-679. 